\title{
A Comparison of the Karyotype of Five Species in Genus Macaca (Primate, Cercopithecidae) in Thailand by Using Conventional Staining, G-banding and High-Resolution Technique
}

\author{
Alongkoad Tanomtong ${ }^{*, 1}$, Sumpars Khunsook ${ }^{1}$, Wiwat Kaensa ${ }^{1}$ and \\ Ruengwit Bunjongrat ${ }^{2}$ \\ ${ }^{1}$ Genetics Program, Department of Biology, Faculty of Science, Khon Kaen University, \\ Khon Kaen, 40002, Thailand \\ ${ }^{2}$ Genetics Program, Department of Botany, Faculty of Science, Chulalongkorn University, \\ Phayathai, Bangkok, 10330, Thailand
}

Received February 7, 2006; accepted March 1, 2006

\begin{abstract}
Summary Cytogenetics of 5 macaque species from genus Macaca in Thailand were studied using lymphocyte cultures and high-resolution techniques. Their chromosome numbers are $2 n=42,20$ pairs of autosome, and 1 pair of sex-chromosome. M. arctoides and M. mulatta have a fundamental number (NF) 84 in male and female but the others have 83 in male and 84 in female. They have 6 large, 4 medium, 8 small metacentric chromosomes and 8 large, 12 medium, 2 small submetacentric chromosomes respectively. M. fascicularis and M. mulatta have medium metacentric X chromosome. M. assamensis, M. nemestrina and M. arctoides have medium submetacentric X chromosome. M. arctoides has small submetacentric $\mathrm{Y}$ chromosomes, M. mulatta has small metacentric $\mathrm{Y}$ chromosomes, while M. assamensis, M. fascicularis and M. nemestrina have small telocentric Y chromosomes. By using G-banding in metaphase and high-resolution technique in late prophase, the results show that the bands are 274, 273, 273, 275, 273 and 351, 350, 350, 352, 350 respectively. Their autosome and X chromosome are similar but their Y chromosome is different. The NOR is on the short arm of chromosome 13. The largest is the metacentric chromosome. The smallest is theY chromosome. Thus $\mathrm{X}$ and $\mathrm{Y}$ chromosomes can use for identification.
\end{abstract}

Key words Macaque, Macaca, Karyotype, G-banding, High-resolution technique.

Over the world, primates are separated into 13 families, 60 genera and 232 species. Three families, 5 genera and 13 species are found in Thailand (Wilson and Cole 2000). Five species are the macaques in genus Macaca. These are stump-tailed macaque (Macaca arctoides: Geoffroy 1831), assam macaque (M. assamensis: McClelland 1839), long-tailed macaque (M. fascicularis: Raffles 1821), rhesus monkey (M. mulatta: Zimmermann 1780) and pigtailed macaque (M. nemestrina: Linnaeus 1766) (Brockelman 2524, Lekagul and McNeely 1977, 1988).

Although cytogenetics of the macaques in genus Macaca have been reported (Chiarelli 1962, Hsu and Benirschke 1967, Napier and Napier 1976, Caballin et al. 1980, Small and Stanyon 1985, Brown et al. 1986 and Hirai et al. 1991), there are few reports of the cytogenetics of the macaques in this genus in Thailand. The macaques in Thailand are conserved animals. They are at risk. In this study, lymphocyte culture, conventional staining, G-banding and the high-resolution technique were used to compare the results with the previous studies. In the future, basic knowledge about macaques and their cytogenetics will be applied for research and to protect them from extinction.

*Corresponding author, e-mail: tanomtong@hotmail.com 


\section{Materials and methods}

M. arctoides, M. assamensis, M. fascicularis, M. mulatta and M. nemestrina were maintained in Nakhonratchasima Zoo, Nakhonratchasima Province and Songkla Zoo, Songkla Province, Thailand. Blood samples from 2 male and 2 female macaques were collected. T-lymphocytes were cultured by the whole blood microculture method. Conventional staining, G-banding and high-resolution technique modified from human (Kumpiranon 1994) were used.

\section{Results}

The chromosome numbers of 5 species of Macaca in Thailand are similar, $2 n=42$. They are composed of 40 autosomes (20 pairs) and 2 sex chromosomes (X and Y chromosome), 1 pair. The results show that all of them have the same fundamental number (NF) in females. $M$. arctoides, $M$. mulatta, M. assamensis, M. fascicularis and M. nemestrina have 84 in female. However the fundamental numbers in male are different. M. arctoides and M. mulatta have 84 but M. assamensis, $M$. fascicularis and M. nemestrina have 83 (Table 1).

All Thai macaques have only 2 types of autosome, metacentric and submetacentric. They have 6 large, 4 medium and 8 small metacentric chromosomes and 8 large, 12 medium and 2 small submetacentric chromosomes (Table 1).

X chromosomes of M. fascicularis and M. mulatta are medium metacentric but M. assamensis, M. nemestrina and $M$. arctoides are medium submetacentric. Y chromosomes of $M$. arctoides are small submetacentric chromosomes, while $M$. mulatta has small metacentric chromosomes. M. assamensis, M. fascicularis and M. nemestrina have small telocentric chromosomes (Table 1).

The genetic marker is the unique chromosome of the living thing. The results suggest that the genetic marker of these macaques is chromosome 13. This is because this chromosome has a secondary constriction and nucleolar organizer region (NOR) on the short arm. The metacentric autosome is the largest chromosome. The Y chromosome is the smallest.

G-banding was used in the metaphase and high-resolution technique was used in the late prophase. The results show that the bands of autosome and sex chromosome are haploid set. The

Table 1. Diploid (2n) and fundamental number (NF) of autosome and sex chromosome of 5 species of macaques in Thailand

\begin{tabular}{|c|c|c|c|c|c|c|c|c|c|c|}
\hline \multirow{3}{*}{ Type of macaques } & \multirow{3}{*}{$\mathrm{NF}$} & \multirow{3}{*}{$2 n$} & \multicolumn{6}{|c|}{ Autosome (pairs) } & \multirow{2}{*}{\multicolumn{2}{|c|}{$\begin{array}{c}\text { Sex } \\
\text { chromosome }\end{array}$}} \\
\hline & & & \multicolumn{3}{|c|}{ Metacentric } & \multicolumn{3}{|c|}{ Submetacentric } & & \\
\hline & & & $\mathrm{L}$ & M & S & $\mathrm{L}$ & M & $\mathrm{S}$ & $\mathrm{X}$ & $\mathrm{Y}$ \\
\hline $\begin{array}{l}\text { Stump-tailed macaque } \\
\text { (Macaca arctoides) }\end{array}$ & $\begin{array}{l}84 \text { in male } \\
\text { and female }\end{array}$ & 42 & 3 & 2 & 4 & 4 & 6 & 1 & $\operatorname{sm}(\mathrm{M})$ & $\operatorname{sm}(\mathrm{S})$ \\
\hline $\begin{array}{l}\text { Assam macaque } \\
\quad(M . \text { assamensis })\end{array}$ & $\begin{array}{l}83 \text { in male } \\
84 \text { in female }\end{array}$ & 42 & 3 & 2 & 4 & 4 & 6 & 1 & $\operatorname{sm}(\mathrm{M})$ & $\mathrm{t}(\mathrm{S})$ \\
\hline $\begin{array}{l}\text { Long-tailed macaque } \\
\text { (M. fascicularis) }\end{array}$ & $\begin{array}{l}83 \text { in male } \\
84 \text { in female }\end{array}$ & 42 & 3 & 2 & 4 & 4 & 6 & 1 & $\mathrm{~m}(\mathrm{M})$ & $\mathrm{t}(\mathrm{S})$ \\
\hline $\begin{array}{l}\text { Rhesus monkey } \\
\qquad(M . \text { mulatta })\end{array}$ & $\begin{array}{l}84 \text { in male } \\
\text { and female }\end{array}$ & 42 & 3 & 2 & 4 & 4 & 6 & 1 & $\mathrm{~m}(\mathrm{M})$ & $\mathrm{m}(\mathrm{S})$ \\
\hline $\begin{array}{l}\text { Pigtailed macaque } \\
(M . \text { nemestrina })\end{array}$ & $\begin{array}{l}83 \text { in male } \\
84 \text { in female }\end{array}$ & 42 & 3 & 2 & 4 & 4 & 6 & 1 & $\operatorname{sm}(\mathrm{M})$ & $\mathrm{t}(\mathrm{S})$ \\
\hline
\end{tabular}

Note: $\mathrm{m}=$ metacentric; $\mathrm{sm}=$ submetacentric; $\mathrm{t}=$ telocentric $\mathrm{L}=$ large chromosome; $\mathrm{M}=$ medium chromosome; $\mathrm{S}=$ small chromosome. 


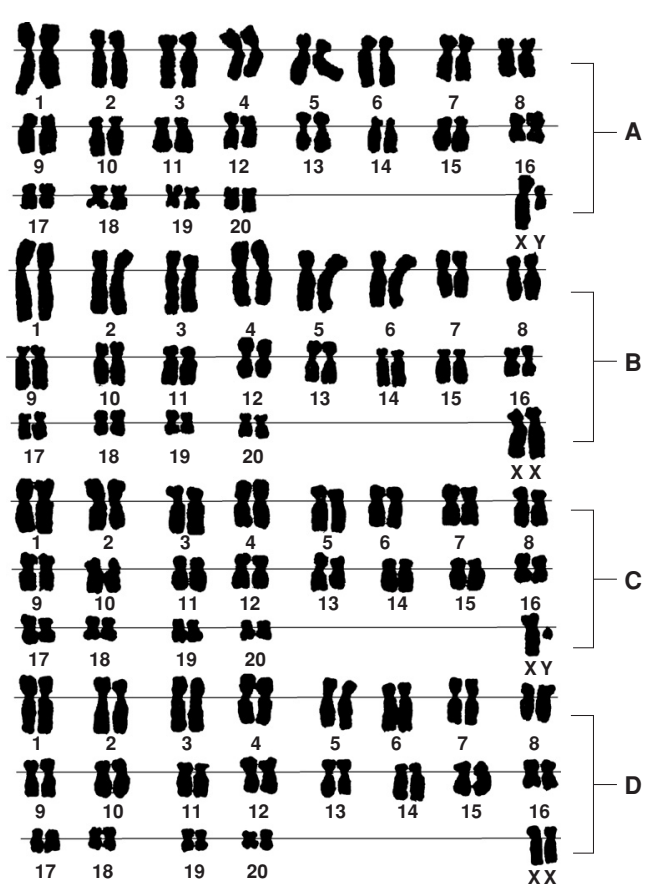

Fig. 1. Karyotype of male (A) and female (B) stumptailed macaque $(M$. arctoides) $2 n$ (diploid) $=42$, male (C) and female (D) assam macaque (M. assamensis) $2 n$ (diploid) $=42$ using conventional staining.

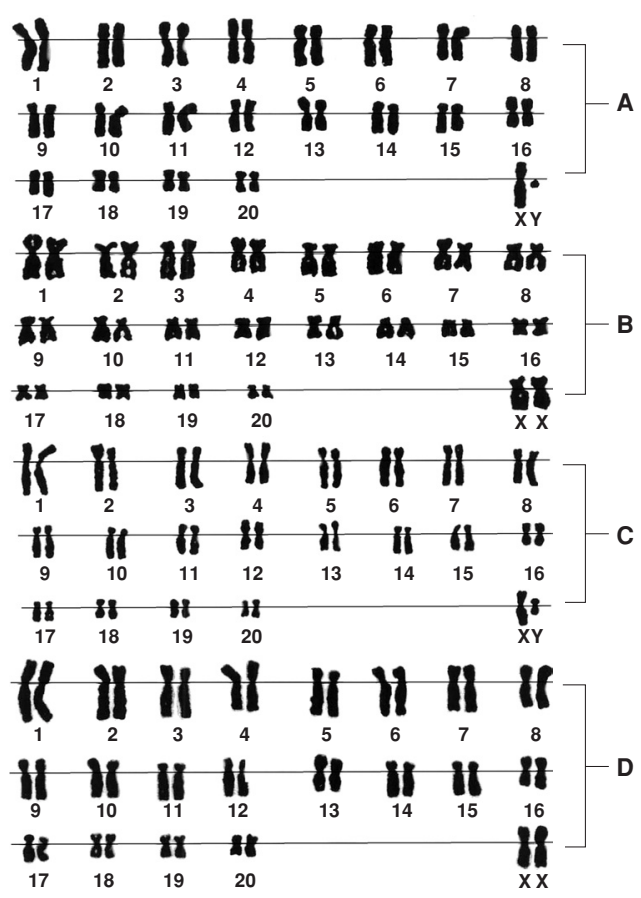

Fig. 2. Karyotype of male (A) and female (B) longtailed macaque (M. fascicularis) $2 n$ (diploid) $=42$, male $(C)$ and female (D) rhesus monkey (M. mulatta) $2 n$ (diploid) $=42$ using conventional staining.

bands in the metaphase are 274, 273,273, 275 and 273 respectively. The bands in the late prophase are $351,350,350,352$ and 350 respectively. The bands of autosome and X chromosome from $M$. arctoides, M. assamensis, $M$. fascicularis, M. mulatta and $M$. nemestrina are similar but the difference occurs in the $\mathrm{Y}$ chromosome.

\section{Discussion}

From this study it was found that the chromosome number and the fundamental number of 5 species of Macaca in Thailand are consistent with Brown et al. (1986). The Macaca, namely M. arctoides, M. fascicularis, M. mulatta, M. nemestrina, Celebes crested, Bonnet and Mangabey in genus Cercocebus have the same chromosome number, $2 n=42$. This research agrees with other previous studies. Hirai et al. (1991) reported that the chromosome numbers of M. arctoides is $2 n=42$ and the NF is 83 in male and female. Napier and Napier (1976), Small and Stanyon (1985) found that the chromosome number of M. mulatta is $2 n=42$.

In this study, the autosomes were different from Brown et al. (1986) who reported that M. arctoides has 14 metacentric and 26 submetacentric chromosomes whereas the chromosomes of $M$. fascicularis, M. mulatta and M. nemestrina were similar, with 18 metacentric and 22 submetacentric. M. fascicularis (Hirai et al. 1991) and M. mulatta (Napier and Napier 1976, Small and Stanyon 1985) are also reported as having 18 metacentric and 22 submetacentric chromosomes.

The results for $\mathrm{X}$ and $\mathrm{Y}$ chromosomes from this research agree with previous reports that indicate that X chromosomes of $M$. arctoides, M. fascicularis, M. mulatta and M. nemestrina are submetacentric, metacentric, metacentric and submetacentric repectively and the $\mathrm{Y}$ chromosome is the 


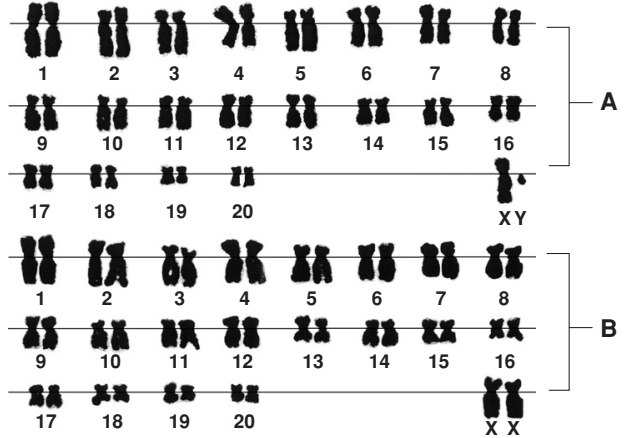

Fig. 3. Karyotype of male (A) and female (B) pigtailed macaque $(M$. nemestrina $) 2 n$ (diploid) $=42$ using conventional staining.

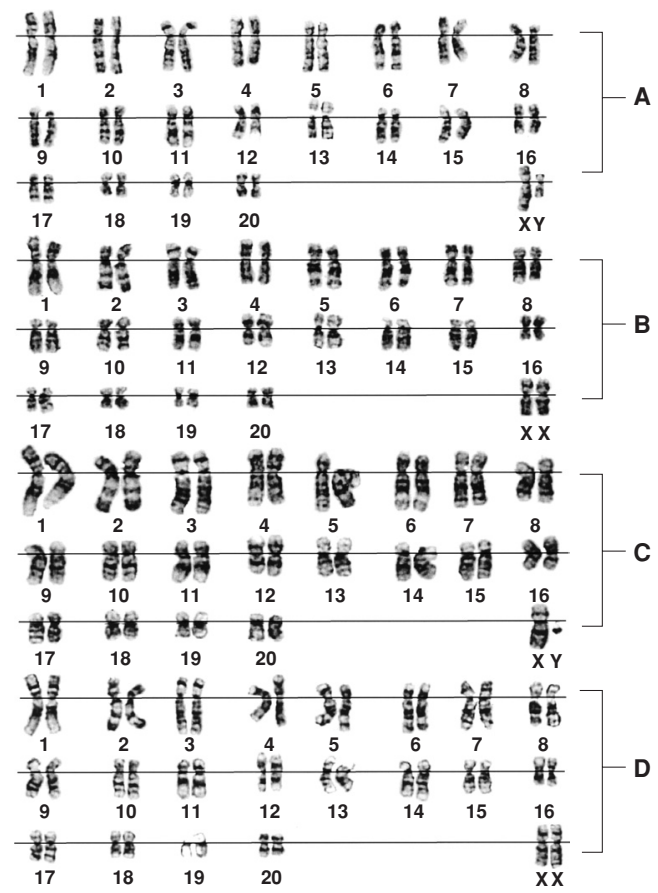

Fig. 4. Karyotype of male (A) and female (B) stumptailed macaque $(M$. arctoides) $2 n$ (diploid) $=42$, male (C) and female (D) assam macaque (M. assamensis) $2 n$ (diploid) $=42$ using G-banding.
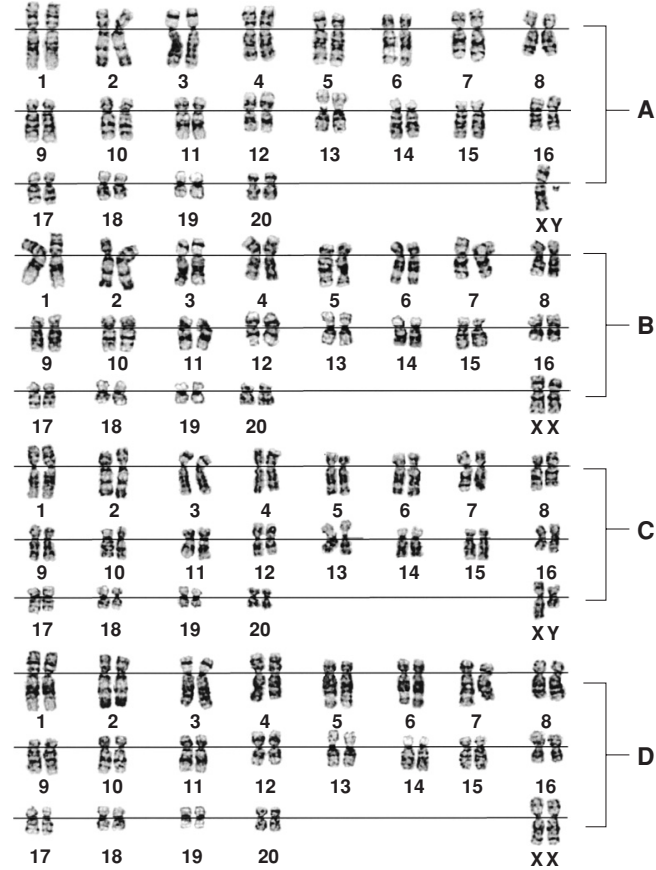

Fig. 5. Karyotype of male (A) and female (B) longtailed macaque (M. fascicularis) $2 n$ $($ diploid $)=42$, male $(C)$ and female (D) rhesus monkey (M. mulatta) $2 n$ (diploid) $=42$ using Gbanding.

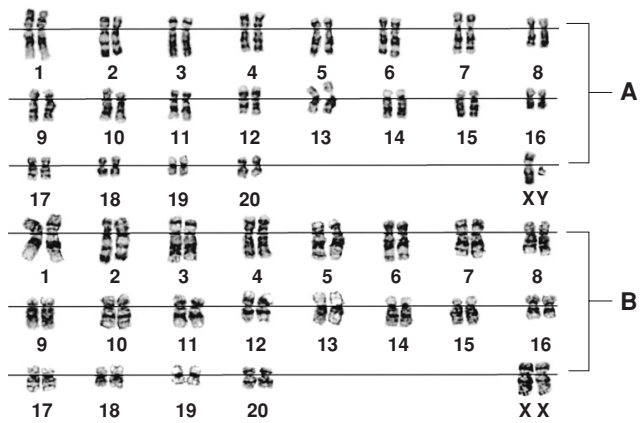

Fig. 6. Karyotype of male (A) and female (B) pigtailed macaque (M. nemestrina) $2 n$ (diploid) $=42$ using G-banding.

smallest (Brown et al. 1986). The $\mathrm{X}$ chromosome of $M$. fascicularis is medium metacentric and the $\mathrm{Y}$ chromosome is the smallest telocentric reported (Hirai et al. 1991). M. assamensis has medium submetacentric X chromosome and the smallest is the Y chromosome (Napier and Napier 1976, Small and Stanyon 1985).

The sex chromosomes of the macaque in genus Macaca has a large shift. Their X and Y chromosomes have different shape and size. The Y chromosome has three types, metacentric, submetacentric and telocentric. The $\mathrm{X}$ chromosome has 2 types, metacentric and submetacentric. According to a previous study it was found that $M$. arctoides, M. fascicularis, M. mulatta, M. nemestrina, 


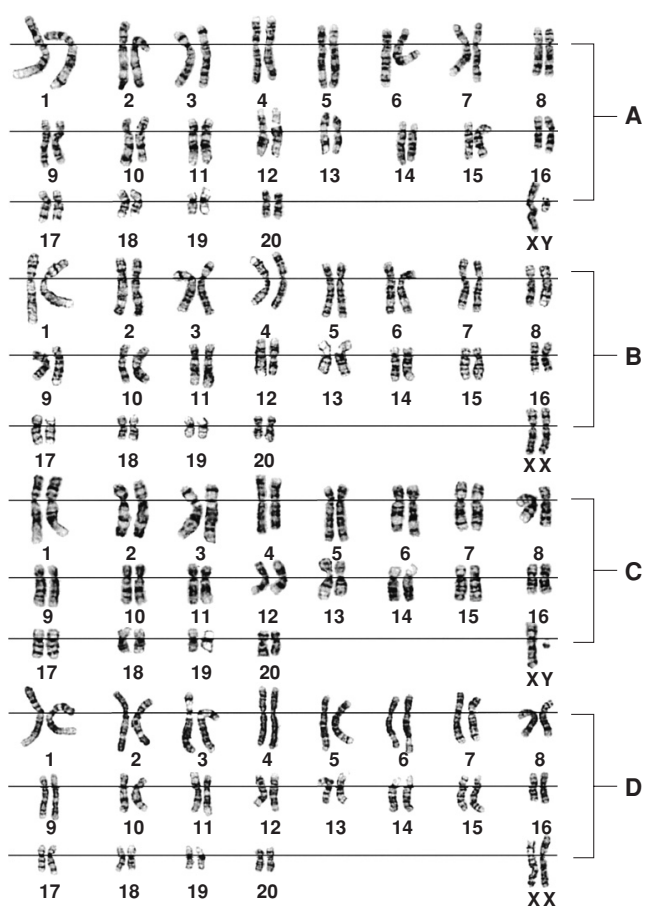

Fig. 7. Karyotype of male (A) and female (B) stumptailed macaque (M. arctoides) $2 n$ (diploid) $=42$, male (C) and female (D) assam macaque (M. assamensis) $2 n$ (diploid) $=42$ using high-resolution.

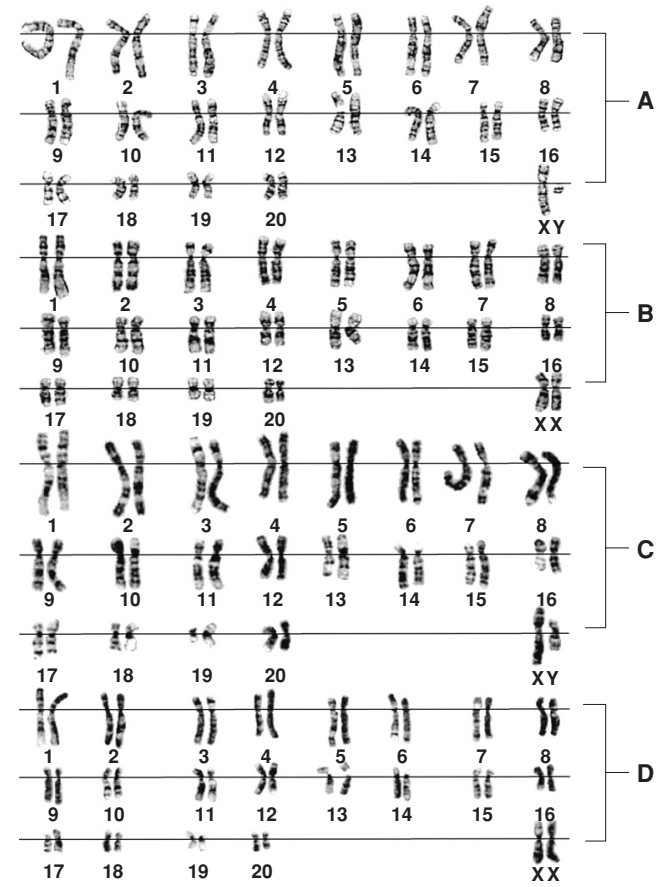

Fig. 8. Karyotype of male (A) and female (B) longtailed macaque (M. fascicularis) $2 n$ (diploid) $=42$, male $(\mathrm{C})$ and female (D) rhesus monkey (M. mulatta) $2 n$ (diploid) $=42$ using high-resolution.

Celebes crested and Bonnet have a large shift in sex chromosome (Brown et al. 1986). The Y chromosome is the smallest and has different sizes. Perhaps the centromere of the chromosome is not shown and the type of chromosome is not separated (Napier and Napier 1976). M. mulatta, M. nemestrina, Japanese monkey and Taiwan monkey (M. cyclopis) have different size and shape of Y chromosome (Hirai et al. 1991). In addition, Stanyon (1983) found the difference of the chromosome of the macaque in genus Cercocebus namely the Japanese monkey and Cercocebus aterrimus by using C-banding.

The genetic marker of the macaque in genus Macaca in Thailand is NOR on the short arm of chromosome 13. This result agrees with the result from Brown et al. (1986) that reported M. arctoides, M. fascicularis, M. mulatta, M. nemestrina, Celebes crested, Bonnet and Mangabey have NOR on the short arm of chromosome 9. The different position of NOR occurred because of the karyotype and the method used to detect the length of the chromosome. Similarly, NORs of baboon and gibbon are on chromosome 1 (Jones et al. 1994). NORs of Japanese monkey and Cercocebus aterrimus are on the short arm of chromosome 13 but the size is different (Stanyon 1983). From observation of the metaphase cell of the macaque in genus Macaca in Thailand, the first pair of chromosomes is the largest distinctive metacentric, while the $\mathrm{Y}$ chromosome is the important chromosome that is used to identify the species of the macaque according to Brown et al. (1986), Napier and Napier (1976), Hirai et al. (1991) and Small and Stanyon (1985).

The chromosome bands of 5 macaques using G-banding and high-resolution technique, showed low sensitivity when compared with the bands in human and ape that showed 1,000 bands per set of haploid chromosome by using G-banding in prophase.

Using high-resolution banding technique for comparison of the chromosomes in Japanese 
monkey and C. aterrimus, the differences in their chromosomes are clear using medium detailed band but the number of bands per set of haploid chromosome are not seen (Stanyon 1983). Yunis (1982) used G-banding for studying the evolution of human, gorilla, orangutan and chimpanzee by comparing the characterization and the bands of the chromosome. The metaphase chromosome showed 320-500 bands and the prophase chro-

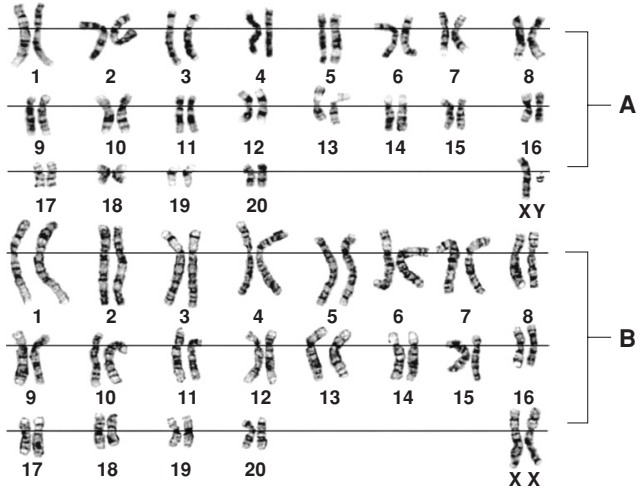

Fig. 9. Karyotype of male (A) and female (B) pigtailed macaque (M. nemestrina) $2 n$ (diploid) $=42$ using high-resolution.

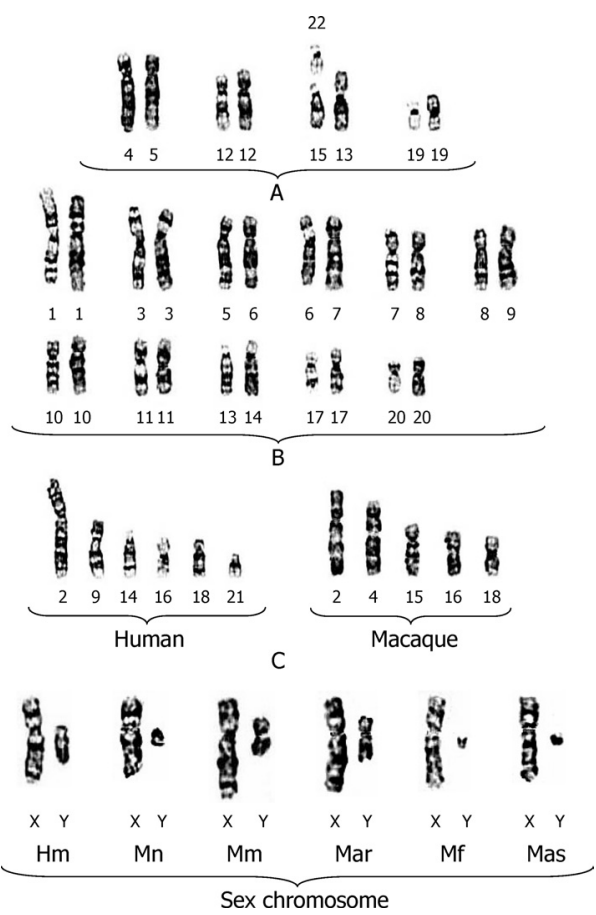

Fig. 10. A comparison of the autosomes between human (left) and macaque (right) show the same (A), similar (B) and different (C) G-banding pattern. And a comparison of sex chromosome show the difference on chromosome Y. (human; Hm, pigtailed macaque; Mn, rhesus monkey; MM, stump-tailed macaque; Mar, long-tailed macaque; Mf and assam macaque; Mas). mosome showed 1,000 bands per set of haploid chromosome. Using G-banding for M. mulatta showed more bands in the late prophase chromosome than the metaphase chromosome. This difference is used to couple the chromosomes and easily check mutation in small points (Small and Stanyon 1985).

\section{Acknowledgement}

The Zoological Park Organization under the Royal Patronage supported this work. We would like to thank Sophon Dumnui (the director of the Zoological Park Organization), the director of Nakhonratchasima Zoo and the director of Songkla Zoo for the blood samples. Thanks to the authorities and officers of these zoos for good cooperation.

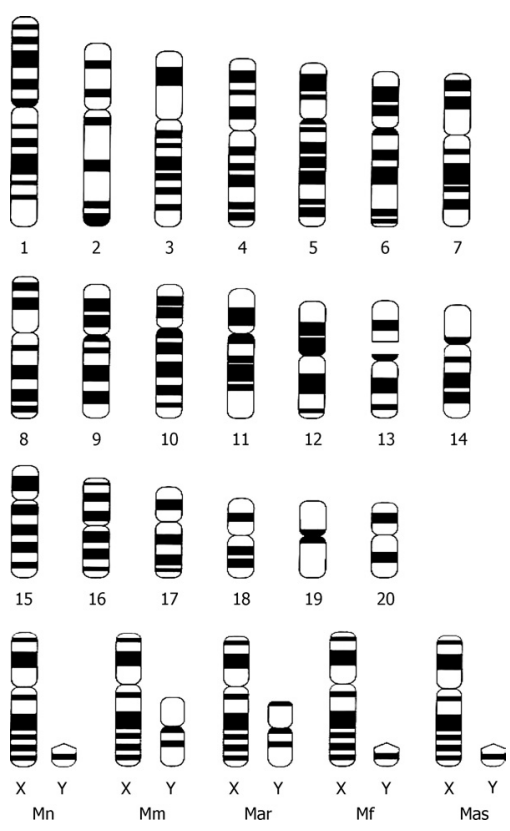

Fig. 11. A comparative idiogram of autosome and sex chromosome between 5 macaque species from genus Macaca in Thailand (pigtailed macaque; Mn, rhesus monkey; MM, stump-tailed macaque; Mar, long-tailed macaque; Mf and assam macaque; Mas). 


\section{References}

Brockelman, W. 1981. The primates in Thailand. Office of the Welfare Promotion Commission for Teachers and Educational Personnel (Kurusapa Business Organization), Bangkok, Thailand.

Brown, C. J., Dunbar, V. G. and Shafer, D. A. 1986. A comparison of the karyotypes of six species of the genus Macaca and a species of the genus Cercocebus. Folia primatol 46: 164-172.

Caballin, M. R., Miro, R., Ponsa, M., Florit, F., Massa, C. and Egozcue, J. 1980. Banding patterns of the chromosomes of Cercophithecus petaurista (Schreber, 1775): comparison with other primate species. Folia primatol 34: 278-285.

Campiranon, A. 1981. Human genetics. Department of Genetics, Faculty of Science, Kasetsart University, Bangkok, Thailand.

Chiarelli, B. 1962. Comparative and morphometric analysis of primate chromosomes: The chromosomes of genera Macaca, Papio, Theropithecus and Cercocebus. Caryologia 15: 401-420.

Hirai, S., Terao, K., Cho, F. and Honjo, S. 1991. Chromosome studies on cynomolgus monkeys (Macaca fascicularis). Primatol Today 24: 619-622.

Hsu, T. C. and Benirschke, K. 1967. An Atlas of Mammalian Chromosomes. Springer Verlag Press, New York.

Jones, S., Martin, R. and Pilbeam, D. Editor 1994. The Cambridge Encyclopedia of Human Evolution. Cambridge University Press, Cambridge.

Lekagul, B. and McNeely, J. A. 1977. Mammals of Thailand. Office of the Welfare Promotion Commission for Teachers and Educational Personnel (Kurusapa Business Organization), Bangkok, Thailand.

— and - 1988. Mammals of Thailand. Saha Karn Bhaet, Bangkok, Thailand.

Napier, J. R. and Napier, P. H. 1976. A Handbook of Living Primates. John Wiley and Sons, New York.

Small, M. F. and Stanyon, R. 1985. High-resolution chromosome of rhesus macaque (Macaca mulatta). Am. J. of Primatol 9: $63-67$.

Stanyon, R., Ardito, G., Lamberti, L. and Bigatti, P. 1983. The banded karyotype of Macaca fuscata compared with Cercocebus aterrimus. Folia Primatol 41: 137-146.

Wilson, D. E. and Cole, F. R. 2000. Common Names of Mammals of the World. Smithsonian Institution Press, Washington. Yunis, J. J. and Prakash, O. 1982. The origin of man: a chromosome pictorial legacy. Science 215: 1525-1530. 